\title{
Individual Leaf Area of Early Flowering Arabidopsis Genotypes Is More Affected by Drought than Late Flowering Ones: A Multi-Scale Analysis in 35 Genetically Modified Lines
}

\author{
Catherine Massonnet ${ }^{1,2,3}$, Myriam Dauzat'1, Alexis Bédiée1, Denis Vile1, Christine Granier1 \\ ${ }^{1}$ Laboratoire d'Ecophysiologie des Plantes sous Stress Environnementaux UMR 759, Institut National de la \\ Recherche Agronomique/Ecole Nationale Supérieure d'Agronomie, Place Viala, Montpellier, France \\ ${ }^{2}$ INRA, UMR Ecologie et Ecophysiologie Forestières, Route d'Amance, Champenoux, France \\ ${ }^{3}$ Université de Lorraine, UMR Ecologie et Ecophysiologie Forestières, Vandoeuvre, France \\ Email: catherine.massonnet@nancy.inra.fr
}

Received 4 March 2015; accepted 12 April 2015; published 16 April 2015

Copyright $@ 2015$ by authors and Scientific Research Publishing Inc.

This work is licensed under the Creative Commons Attribution International License (CC BY). http://creativecommons.org/licenses/by/4.0/

c) (i) Open Access

\begin{abstract}
Plants acclimate to drought optimizing the trade-off between biomass production and water loss while ensuring their survival and reproduction. Plants also modify their growth or phenology as complementary strategies in response to stress. Despite evidence of an interaction between flowering time and plant growth response to environmental stresses, this interaction in response to drought is under debate. To contribute to the analysis of this interaction, leaf growth of 35 genetically modified lines of Arabidopsis thaliana and their common wild-type, Col-0 was analyzed by a quantitative multi-scale phenotyping approach from cellular to whole plant scale both in wellwatered and soil moderate water deficit conditions. These genotypes were selected for the various physiological functions potentially altered by their genetic modification and that could interact with plant growth and/or their drought responses. In all genotypes, leaf expansion decreased in response to drought both at the whole rosette and the individual leaf levels. Additionally, epidermal cell area and/or epidermal cell number decreased in response to the drought treatment. In contrast, the number of rosette leaves was reduced in only half of the genotypes and leaf growth duration was only modified in 4 of them. Despite long photoperiod conditions, the duration of the vegetative phase, i.e. the time elapsed between germination and flowering stage, varied from 12 to 27 days among genotypes under well watered conditions. Our analyses revealed that the differences of flowering time observed in well-watered condition impacted the leaf area response to drought. Early-flowering genotypes slightly decreased their final leaf number, but strongly reduced their
\end{abstract}

How to cite this paper: Massonnet, C., Dauzat, M., Bédiée, A., Vile, D. and Granier, C. (2015) Individual Leaf Area of Early Flowering Arabidopsis Genotypes Is More Affected by Drought than Late Flowering Ones: A Multi-Scale Analysis in 35 Genetically Modified Lines. American Journal of Plant Sciences, 6, 955-971. http://dx.doi.org/10.4236/ajps.2015.67102 
individual leaf area compared with the late-flowering ones. This result underlines the difficulty to analyze plant response to environmental stresses when genotypes with different flowering dates are compared.

\section{Keywords}

\section{Arabidopsis thaliana, Soil Water Deficit, Leaf Area, Leaf Expansion, Flowering Time}

\section{Introduction}

Understanding how plants are facing drought stress is a central concern and consequently it has been the subject of many studies and reviews [1]-[3]. Under drought, plants combine both developmental and growth modifications to ensure their survival and reproduction on the one hand and to optimize the trade-off between biomass production and water loss on the other hand. Plants responses to drought are often separated into "drought escape strategy", when plants accelerate their development in order to complete their life cycle before the period of severe stress or "dehydration avoidance strategy" when plants set up a suite of phenological, morphological and physiological adjustments to avoid desiccation during the stress period and consequently complete their life cycle often with a delay [4]-[7]. In Arabidopsis thaliana, the multiscale analysis of shoot growth in plants subjected to drought revealed a complex integrated response. Compensations occur at several scales depending on the water deficit scenario, i.e. the rate at which soil water content decreases, the stress intensity and duration, and the developmental stage reached by the plant when the stress occurs [3]. A common response to different water deficit scenarios is the reduction of leaf expansion, which is interpreted as a strategy to limit water losses by reducing evaporative surface. However, depending on stress intensity, soil water deficits that reduce leaf expansion do not necessarily affect carbon metabolism, transcripts and proteins productions [8]. In many examples, leaves exposed to a mild soil water deficit present an adaptive response with a reduction of cell division and/or cell expansion, a maintenance of net photosynthesis and a lengthening of leaf expansion duration [2] [3] [9] [10]. The molecular control of this adaptation to a mild water deficit at the leaf scale differs from the ones reported for severe drought stresses or osmotic shocks [2] [8] [11] [12]. Many studies based on the natural variation in $A$. thaliana showed that the modification of leaf expansion by drought was genetically controlled and that polymorphism existed among $A$. thaliana ecotypes [9] [13] [14]. Different populations of recombinant inbred lines have also been studied to identify Quantitative Trait Loci that control leaf growth response to soil water deficit [15]-[19]. These studies led to the identification of many flowering time related polymorphisms. This is not surprising as it is reported in many studies that flowering time strongly impacts leaf growth. The duration of the vegetative phase is related to many other shoot growth related variables, including the number of leaves produced by the plant [15], more intriguingly individual leaf expansion and epidermal cell expansion in individual leaves [18] [20]. A delay in flowering date causes an increase in leaf number, in the duration of leaf expansion, and in epidermal cell area in leaves, and all these changes interact to impact whole shoot development and leaf expansion.

The role of flowering genes in the control of leaf growth was demonstrated in various studies [21]-[24]. The variations found for leaf growth and flowering time and their drought responses have been analyzed among natural Arabidopsis thaliana accessions and recombinant inbred line populations. However, the relationship between flowering time, leaf production and leaf expansion is not always clear and leads to different conclusions depending on the study. Within a set of 25 natural accessions, there was no relationship between flowering time and leaf growth response to drought [9]. In contrast, in the Ler x An-1 RIL population, late flowering lines better maintained their whole rosette expansion and individual leaf area in response to water deficit [18] [19], whereas in another study early flowering accessions were those that maintained their leaf expansion [13] [25].

The identification of molecular networks controlling the response of leaf expansion to water deficit (or to another treatment that would also affect jointly flowering time and leaf growth) is hampered by the relationship between flowering time and leaf growth at different scales. Is it really possible to analyze the response of plant leaf growth to drought without considering plant reproductive performance? In this context and with the aim to carry a contribution to this debate, we analyzed the leaf growth performance of 36 genotypes under moderate soil water deficit conditions by a multi-scale leaf growth phenotyping approach. Whereas many previous studies 
have focused on the impacts of extreme climatic events such as severe drought stress, under temperate climate, a moderate but continuous soil water deficit may occur and affect also plant productivity. In the present study, we compared leaf growth and its response to a moderate and stable soil water deficit imposed during the whole plant cycle except germination. In contrast to similar studies that have assessed this question in natural accessions, recombinant inbred lines or near-isogenic lines, we selected for our study a set of mutants impaired in different functional pathways including carbohydrate metabolism, circadian clock, signaling or hormonal status. These mutants were selected for an expected variability in leaf growth under well-watered condition and/or in the soil water deficit regime. The aim of this work was also to explore whether certain specific physiological pathways are more significant than others in mediating leaf growth responses to drought, and could be advantageous for maintaining leaf growth under a continuous mild water deficit. We explored the relationships between the duration of the vegetative phase and the leaf growth performance in response to a moderate soil water deficit condition. Our results illustrate the complexity to conclude about how a (single) mutation impacts shoot growth and its plasticity when this mutation also affects whole plant growth duration among genotypes and conditions.

\section{Materials and Methods}

\subsection{Plant Material and Growth Conditions}

A set of 36 genotypes listed in Table 1 were grown in 10 replicates pots in the PHENOPSIS automated phenotyping platform [13]. They included ems mutant, knock-out, transgenic OE or knock-downs and all lines were in the Col-0 background, cleaned up and homozygous. These mutants were affected in genes encoding proteins known to control processes related to plant carbon metabolism, circadian clock, signaling or hormonal status in Arabidopsis thaliana (Table 1).

All micro-meteorological conditions were controlled to remain constant over the experiment and homogeneous across the growth-chamber [13]. Day-length was maintained at $16 \mathrm{~h}$ and light was provided by HQi lamps and additional cool white fluorescent tubes. Incident light was measured continuously at the plant level, using a photosynthetic photon flux density (PPFD) sensor (LI-190SB, LICOR, Lincoln, Nebraska, USA) and daily incident PPFD was calculated by multiplying day-length and mean instantaneous incident PPFD. It reached a mean value of $10 \mathrm{~mol} \cdot \mathrm{m}^{-2} \cdot \mathrm{d}^{-1}$ over the whole period of the experiment. Air temperature and relative humidity were measured every $20 \mathrm{~s}$ (HMP35A Vaisala Oy, Helsinki, Finland) and reached a mean value of $21^{\circ} \mathrm{C}$ and $70 \%$, respectively. All measurements of temperature, PPFD and relative humidity were averaged and stored every 600 $\mathrm{s}$ in a datalogger (Campbell Scientific, LTD-CR10 Wiring Panel, Shepshed, Leicestershire, England). All detailed environmental data, including daily soil water content, air temperature and VPDair, are available in the PHENOPSIS database [26].

Two to three seeds were sown at the soil surface in $225 \mathrm{ml}$ conical pots $(9 \mathrm{~cm}$ height and $4.5 \mathrm{~cm}$ diameter $)$ filled with a mixture $(1: 1, \mathrm{v} / \mathrm{v})$ of a loamy soil and organic compost (Neuhaus N2). Each individual pot was weighted before and after soil filling. Soil water content, was determined at sowing on samples of soil and reached $0.32 \mathrm{~g}$ of $\mathrm{H}_{2} \mathrm{O} \cdot \mathrm{g}^{-1}$ dry soil. Subsequent changes in pot weight were attributed to a change in soil water content without correction by the weight of the plants because preliminary experiments showed that weight of the plants for this set of genotypes grown in these conditions modified the estimated soil water content by less than $1.5 \%$. Soil water content was calculated from pot weight and was adjusted automatically with the automaton in the PHENOPSIS platform (as described in [13] and [26]). First, all replicates were grown with a daily adjustment of soil water content to $0.35 \mathrm{~g} \cdot \mathrm{H}_{2} \mathrm{O} \cdot \mathrm{g}^{-1}$ dry soil from germination until emergence of the first true pair of leaves (growth stage 1.02, according to [27]). From this stage, half of the replicates were subjected to an optimal watering treatment with a daily adjustment of soil water content to $0.40 \mathrm{~g} \cdot \mathrm{H}_{2} \mathrm{O} \cdot \mathrm{g}^{-1}$ dry soil. For the other half, irrigation was stopped during a few days (4 to 5 depending on the genotype) until soil water content reached $0.23 \mathrm{~g} \cdot \mathrm{H}_{2} \mathrm{O} \cdot \mathrm{g}^{-1}$ dry soil. Soil water content was then maintained at this value until the end of rosette leaf development and this corresponded to a moderate soil water deficit in our conditions [13]. All soil water content adjustments were done pot per pot according to individual plant developmental stage.

\subsection{Growth Measurements}

Digital pictures of all individual pots were taken automatically on a daily basis during the whole experiment [13] from emergence of the first two leaves (stage 1.02) until first flower open (stage 6.00, as defined in [27]) which 
Table 1. List of the 35 genotypes grown with the Col-0 wild-type in the PHENOPSIS platform both in well-watered condition and a moderate soil water deficit.

\begin{tabular}{|c|c|c|}
\hline Genotypes & Modified functions & References \\
\hline bam 1 & Starch utilization at night & {$[50]$} \\
\hline bam 1 bam 3 & Starch utilization at night & {$[50]$} \\
\hline bam 3 & Starch utilization at night & {$[50]$} \\
\hline dpe 1 & Starch utilization at night & {$[51]$} \\
\hline dpe 2 & Starch utilization at night & {$[51]$} \\
\hline $\operatorname{mex} 1$ & Starch utilization at night & {$[52]$} \\
\hline $\operatorname{sex} 1$ & Starch utilization at night & {$[53]$} \\
\hline pgm & Starch synthesis & {$[54]$} \\
\hline tpt & Translocation of photosynthates & {$[55]$} \\
\hline TRE1-OE & Trehalose accumulation & {$[56]$} \\
\hline tre 1 & Trehalose accumulation & {$[56]$} \\
\hline elf3-1 & Circadian clock & {$[57]$} \\
\hline elf $3-7$ & Circadian clock & [57] \\
\hline prr5-prr 9 & Circadian clock & [58] \\
\hline prr9-1 & Circadian clock & [58] \\
\hline ein2 & Ethylene signal & [59] \\
\hline etr 1 & Ethylene signal & [60] \\
\hline jar 1 & Jasmonate signal & [61] \\
\hline$n p r 1$ & Salicylic acid signal & {$[62]$} \\
\hline pad4 & Salicylic acid signal & [63] \\
\hline $\operatorname{sid} 2$ & Salicylic acid signal & [64] \\
\hline anac 055 & Regulation of transcription & [65] \\
\hline ataf 1 & Regulation of transcription & [66] \\
\hline $\operatorname{im} 24$ & Regulation of transcription & Unpublished \\
\hline $\operatorname{im} 38$ & Regulation of transcription & Unpublished \\
\hline $\operatorname{im} 4$ & Regulation of transcription & Unpublished \\
\hline $\operatorname{im} 56$ & Regulation of transcription & Unpublished \\
\hline$m y b 112$ & Regulation of transcription & {$[67]$} \\
\hline$m y b 2$ & Regulation of transcription & [67] \\
\hline myb59 & Regulation of transcription & [67] \\
\hline$m y b 74$ & Regulation of transcription & [67] \\
\hline$n a c$ & Regulation of transcription & {$[68]$} \\
\hline nap & Regulation of transcription & [69] \\
\hline pap1-myb75 & Regulation of transcription & [70] \\
\hline$r d 26$ & Regulation of transcription & [68] \\
\hline
\end{tabular}


corresponds to the end of rosette leaf expansion in Arabidopsis thaliana (not shown). On these pictures, stages of leaf development were manually scored three times a week, for each individual plant as described in [27]. For each plant, flowering time was defined as the duration of rosette development and was determined as the time elapsed between stage 1.02 and 6.00 to overcome the variability of germination time among plants. At stage 6.00 , the rosettes were cut, leaves were detached, and laminas were separated from the petiole. They were stuck with double side adhesive on a sheet of paper in their order of emergence on the rosette. The leaves were then scanned for further measurements using an Image $J$ macro developed in our group and available on the PHENOPSIS database interface [26]. Individual leaf area was measured on the leaf scans. Rosette area was determined as the sum of the individual leaf blade areas and the number of rosette leaves was estimated by counting the number of leaves produced after the two cotyledons. In addition, a transparent negative film of the adaxial epidermis of the 6th leaf was obtained after evaporation of a transparent nail varnish spread on the surface of the leaf. Films of epidermal imprints were placed under a microscope (Leica, Leitz DM RB, Wetzlar, Germany) coupled to an image analyzer. Epidermal cell area was estimated by measuring 25 epidermal cell areas drawn manually at two different zones on each leaf, near the base, near the tip of the leaf with an image analysis software (Bioscan-Optimas V 4.10, Edmonds, WA). Mean epidermal cell area was calculated as the mean of these 50 cells. Mean epidermal cell density was estimated by counting the number of epidermal cells in the same two different zones on each leaf. Epidermal cell number was estimated from mean epidermal cell density multiplied by the corresponding 6th leaf area.

\subsection{Statistical Analyses}

Statistical analyses were done using the R software [28]. Traits variations between treatments were tested by two-way ANOVA using genotype and soil water content as factors. For each environmental condition Pairwise differences between the wild-type and each mutant were tested by ANOVA with planned comparisons with Bonferroni p-value correction for multiple testing. A Principal Component Analysis (PCA) was performed to explain multivariate growth variance in relation to soil water regimes. Difference between treatments was tested with a randomization test (randtest between in the R/ade4 package). The relative response of each variable to water deficit was calculated for each line as the difference between the value in well-watered condition and the value in water deficit condition divided by the value in well-watered condition. These relative responses to soil water deficit were represented for each genotype in a heat map and were compared between genotypes by a hierarchical clustering analysis using Euclidian distances. Linear relationships for each variable measured in the 36 genotypes were established between the two water regimes and were tested with correlation coefficients. The relationships between the relative response to soil water deficit of leaf number, individual leaf area and rosette leaf area in the 36 genotypes and the duration of rosette expansion were also tested with correlation coefficients.

\subsection{Data Access}

All meteorological and phenotypical data will be publicly available with all plant scans and rosette images in the PHENOPSIS database [26] (http://bioweb.supagro.inra.fr/phenopsis/) after paper publication.

\section{Results}

\subsection{A Single Mutation Can Have Various Impacts on Leaf Growth According to the Soil Water Regime}

Rosette growth was analyzed with a multi-scale approach in a set of 35 genetically modified genotypes and their common wild-type, Columbia-0 (Table 1), both under well-watered and a moderate soil water deficit conditions (Table 2).

Under well-watered condition, among the 35 mutants, 20 changed significantly their rosette area compared to the wild-type (Table 2). Only 2 of them, prr5-prr 9 and pap1-myb75, showed a positive impact of the mutation on rosette area that was increased by $187 \%$ and $41 \%$, respectively compared to the wild-type. Rosette area was decreased in the 18 other genotypes by $42 \%$ to $87 \%$. These significant changes in rosette leaf area were mainly related to changes in individual leaf areas. Among these 20 mutants, 16 also showed a significant change in individual leaf 6 area whereas only 8 showed a significant change in final leaf number. In the prr5-prr 9 mutant, the high increase in rosette leaf area was due to a strong increase in leaf number. 
Table 2. Variation of leaf growth traits within the set of 36 genotypes grown under well-watered and water deficit conditions. In the table mean + standard deviation values are noted for 6 variables of growth. The traits are: duration of rosette expansion (day), rosette leaf number at flowering, rosette leaf area at flowering $\left(\mathrm{cm}^{2}\right)$, leaf 6 area at flowering $\left(\mathrm{cm}^{2}\right)$, mean cell area in the upper epidermis of mature leaf $6\left(\mu \mathrm{m}^{2}\right)$ and cell number in the upper epidermis of mature leaf 6 . The genotypes are ranked by alphabetical order after the wild type.

\begin{tabular}{|c|c|c|c|c|c|c|c|c|c|c|c|c|}
\hline \multirow[b]{2}{*}{ Genotypes } & \multicolumn{6}{|c|}{ Well watered condition } & \multicolumn{6}{|c|}{ Water deficit condition } \\
\hline & Duration & $\begin{array}{c}\text { Leaf } \\
\text { number }\end{array}$ & $\begin{array}{c}\text { Rosette } \\
\text { area }\end{array}$ & Leaf area & Cell area & Cell number & Duration & $\begin{array}{c}\text { Leaf } \\
\text { number }\end{array}$ & $\begin{array}{c}\text { Rosette } \\
\text { area }\end{array}$ & Leaf area & Cell area & Cell number \\
\hline Col-0 & & & $12.0 \pm 3.2$ & & & & & & & & & 27,86 \\
\hline anac 055 & $16.5 \pm 1.5$ & $8.5 \pm 1$ & $2.6 \pm 0.9$ & $0.40 \pm 0.16$ & $1913 \pm 589$ & $21,392 \pm 6976$ & $19.6 \pm 2.9$ & $7.5 \pm 1.5$ & $0.9 \pm 0.6$ & $0.11 \pm 0.06$ & $937 \pm 340$ & $10,905 \pm 7461$ \\
\hline ataf1 & $16.8 \pm 1.8$ & $9.9 \pm 1.3$ & $4.9 \pm 3.4$ & $0.50 \pm 0.22$ & $1675 \pm 291$ & $26,511 \pm 11,164$ & $17.5 \pm 2.1$ & $8.7 \pm 0.8$ & $1.5 \pm 0.5$ & $0.21 \pm 0.07$ & $1259 \pm 75$ & $16,062 \pm 5196$ \\
\hline bam 1 & $18 \pm 1.6$ & $10.2 \pm 1.1$ & $9.4 \pm 1.8$ & $1.12 \pm 0.13$ & $3297 \pm 445$ & $34,871 \pm 10,830$ & $17.2 \pm 1.8$ & $9.3 \pm 1.6$ & $4.1 \pm 1.1$ & $0.46 \pm 0.08$ & $2047 \pm 181$ & $23,727 \pm 7090$ \\
\hline bam 1 bam3 & $19.2 \pm 2.4$ & $10.1 \pm 1.2$ & $7.0 \pm 2.6$ & $0.76 \pm 0.16$ & $2396 \pm 271$ & $30,696 \pm 6340$ & $20 \pm 1.8$ & $8.4 \pm 0.7$ & $2.2 \pm 0.5$ & $0.34 \pm 0.1$ & $1849 \pm 100$ & $21,728 \pm 7729$ \\
\hline bam3 & $21.8 \pm 1.4$ & $11.3 \pm 1.4$ & $10.9 \pm 3.2$ & $0.93 \pm 0.18$ & $3172 \pm 814$ & $36,421 \pm 5118$ & $23 \pm 3.4$ & $9.6 \pm 1.3$ & $4.3 \pm 2.5$ & $0.43 \pm 0.1$ & $1954 \pm 869$ & $24,100 \pm 2735$ \\
\hline dpe 1 & $20.2 \pm 1.7$ & $11.2 \pm 1$ & $8.5 \pm 3.3$ & $0.74 \pm 0.35$ & $2443 \pm 583$ & $49,670 \pm 13,260$ & $19.6 \pm 1.1$ & $9.8 \pm 0.9$ & $3.1 \pm 0.9$ & $0.36 \pm 0.09$ & $1372 \pm 124$ & $26,864 \pm 4328$ \\
\hline dpe2 & $21.4 \pm 1.1$ & $10.3 \pm 1.2$ & $4.9 \pm 1.8$ & $0.51 \pm 0.13$ & $2441 \pm 239$ & $24112 \pm 6045$ & $19.5 \pm 2$ & $8.9 \pm 0.8$ & $2.1 \pm 0.8$ & $0.29 \pm 0.11$ & $1621 \pm 210$ & $18,768 \pm 5842$ \\
\hline $\operatorname{ein} 2$ & $18.2 \pm 0.4$ & $11.3 \pm 2.5$ & $5.7 \pm 3.3$ & $0.70 \pm 0.48$ & $2536 \pm 209$ & $37,920 \pm 20,669$ & $19.7 \pm 1.9$ & $10.7 \pm 1.6$ & $4.9 \pm 1.6$ & $0.5 \pm 0.11$ & $1891 \pm 132$ & $27,195 \pm 7829$ \\
\hline elf3-1 & $12.7 \pm 0.6$ & $5 \pm 1$ & $1.8 \pm 0.6$ & $0.59 \pm 0$ & $2542 \pm 307$ & $31,004 \pm 0$ & $12.7 \pm 0.8$ & $5.2 \pm 0.4$ & $0.9 \pm 1.2$ & $0.19 \pm 0$ & $1751 \pm 262$ & $10,894 \pm 0$ \\
\hline elf3-7 & $12.6 \pm 0.8$ & $4.9 \pm 0.9$ & $1.6 \pm 0.8$ & $0.55 \pm 0.24$ & $2382 \pm 167$ & $34,699 \pm 355$ & $12.3 \pm 0.5$ & $5 \pm 0.8$ & $0.9 \pm 0.2$ & $0.24 \pm 0$ & $1620 \pm 53$ & $14,794 \pm 0$ \\
\hline etr 1 & $25 \pm 2.3$ & $17.2 \pm 3.6$ & $12.1 \pm 5.7$ & $0.84 \pm 0.27$ & $2396 \pm 1005$ & $35,573 \pm 12,597$ & $21.8 \pm 1.3$ & $11.8 \pm 0.4$ & $6.6 \pm 2.5$ & $0.55 \pm 0.2$ & $2215 \pm 664$ & $29,927 \pm 10,05$ \\
\hline im 24 & $18.3 \pm 1.7$ & $11.1 \pm 4.2$ & $10.5 \pm 5.5$ & $1.02 \pm 0.26$ & $2845 \pm 348$ & $52,862 \pm 6688$ & & $9.1 \pm 1.2$ & $3.7 \pm 1.1$ & $0.51 \pm 0.1$ & $1370 \pm 199$ & $27,190 \pm 5527$ \\
\hline im38 & $18 \pm 0.9$ & $10.8 \pm 0.5$ & $11.2 \pm 3$ & $1.11 \pm 0.26$ & $2655 \pm 241$ & $42,805 \pm 9008$ & $16.7 \pm 0.9$ & $9.2 \pm 1$ & $3.6 \pm 0.7$ & $0.47 \pm 0.1$ & $1328 \pm 90$ & $29,525 \pm 7699$ \\
\hline im4 & $19 \pm 1.2$ & $12 \pm 1$ & $14.0 \pm 2.1$ & $1.18 \pm 0.18$ & $2535 \pm 86$ & $56,937 \pm 8809$ & $18.4 \pm 1.4$ & $9.9 \pm 0.9$ & $5.0 \pm 1.4$ & $0.56 \pm 0.13$ & $2067 \pm 559$ & $28,803 \pm 7539$ \\
\hline $\operatorname{im} 56$ & $17.1 \pm 1.2$ & $10.7 \pm 1.1$ & $12.5 \pm 3.6$ & $1.30 \pm 0.20$ & $2931 \pm 650$ & $55,369 \pm 3502$ & $17.2 \pm 1.8$ & $9.7 \pm 1.3$ & $4.2 \pm 1.7$ & $0.47 \pm 0.08$ & $1604 \pm 196$ & $30,286 \pm 7128$ \\
\hline jar1 & $16.2 \pm 1.2$ & $7.9 \pm 0.9$ & $6 \pm 2.3$ & $1.09 \pm 0.11$ & $2568 \pm 351$ & & & & $2.1 \pm 1.1$ & & & \\
\hline $\operatorname{mex}$ & $19 \pm 2.4$ & $8.7 \pm 0.5$ & $2.3 \pm 0.4$ & $0.30 \pm 0.05$ & $1621 \pm 92$ & $17,427 \pm 4477$ & $17.9 \pm 0.9$ & $7.8 \pm 0.4$ & $1.2 \pm 0.3$ & $0.20 \pm 0.04$ & $1353 \pm 747$ & $16,642 \pm 2786$ \\
\hline myb112 & $18.9 \pm 1.2$ & $11.3 \pm 1.2$ & $12.6 \pm 3$ & $1.14 \pm 0.17$ & $3000 \pm 297$ & $25,662 \pm 5798$ & $17.6 \pm 0.8$ & $9.9 \pm 0.7$ & $4.1 \pm 0.8$ & $0.49 \pm 0.05$ & $1788 \pm 177$ & $21,310 \pm 2695$ \\
\hline myb2 & $19.4 \pm 1.9$ & $11.2 \pm 2$ & $7.6 \pm 4.4$ & $0.67 \pm 0.16$ & $3061 \pm 453$ & $21,464 \pm 3431$ & $18.6 \pm 0.7$ & $8.5 \pm 1.1$ & $1.2 \pm 0.4$ & $0.18 \pm 0.05$ & $1349 \pm 173$ & $12,916 \pm 1966$ \\
\hline myb59 & $18.8 \pm 1.2$ & $10.9 \pm 0.9$ & $11.5 \pm 1.3$ & $1.02 \pm 0.14$ & $2848 \pm 479$ & $27,105 \pm 1377$ & & $10 \pm 0.6$ & $5 \pm 0.6$ & $0.59 \pm 0.07$ & $1837 \pm 144$ & $25,279 \pm 3108$ \\
\hline myb74 & $19.4 \pm 2.4$ & $10.8 \pm 1.8$ & $5.4 \pm 4.6$ & $0.52 \pm 0.35$ & $2246 \pm 203$ & $23,359 \pm 6177$ & & $9.4 \pm 1.5$ & $3.1 \pm 2.6$ & $0.35 \pm 0.17$ & $1606 \pm 265$ & $19,881 \pm 4048$ \\
\hline nac & $18 \pm 2.5$ & $9.3 \pm 1.8$ & $1.6 \pm 0.9$ & $0.18 \pm 0.07$ & $1242 \pm 234$ & $14,933 \pm 9647$ & $21.3 \pm 3.3$ & $8.8 \pm 1.2$ & $1 \pm 0.7$ & $0.13 \pm 0.13$ & $905 \pm 477$ & $12,511 \pm 6403$ \\
\hline nap & $17.4 \pm 0.5$ & $9.4 \pm 0.8$ & $1.9 \pm 1$ & $0.19 \pm 0.06$ & $1373 \pm 156$ & $16,264 \pm 4632$ & $24.8 \pm 4.8$ & $9 \pm 2.2$ & $0.5 \pm 0.3$ & $0.07 \pm 0.04$ & $746 \pm 19$ & $8645 \pm 2419$ \\
\hline npr1 & $13.7 \pm 0.5$ & $6 \pm 0.6$ & $1.6 \pm 0.6$ & $0.38 \pm 0.11$ & $1583 \pm 74$ & $19,584 \pm 3268$ & $17.4 \pm 3.1$ & $5.9 \pm 0.6$ & $0.4 \pm 0.2$ & $0.13 \pm 0.08$ & $1414 \pm 326$ & $8264 \pm 2279$ \\
\hline pad4 & $18.7 \pm 1.7$ & $11 \pm 1$ & $8.5 \pm 1.9$ & $0.74 \pm 0.17$ & $2324 \pm 403$ & $22,514 \pm 7966$ & $18.1 \pm 0.9$ & $10 \pm 1.1$ & $3.4 \pm 1.1$ & $0.39 \pm 0.09$ & $1713 \pm 256$ & $24,070 \pm 3627$ \\
\hline pap1-myb75 & $19.3 \pm 2.1$ & $12 \pm 1.8$ & $17 \pm 7$ & $1.41 \pm 0.3$ & $2529 \pm 221$ & $37,937 \pm 3974$ & $17.6 \pm 1.2$ & $10.2 \pm 1.5$ & $5.2 \pm 1.7$ & $0.57 \pm 0.09$ & $1769 \pm 126$ & $28,361 \pm 6009$ \\
\hline pgm & $21.3 \pm 1.2$ & $9.6 \pm 1.4$ & $5.1 \pm 2.5$ & $0.6 \pm 0.2$ & $2059 \pm 387$ & $26,998 \pm 8073$ & & $9.5 \pm 1.3$ & $3.2 \pm 0.4$ & $0.37 \pm 0.15$ & $1956 \pm 191$ & $19,510 \pm 5364$ \\
\hline prr 5 prr 9 & $27 \pm 1.2$ & $21.8 \pm 2$ & $34.5 \pm 4.5$ & $1.14 \pm 0.29$ & $2403 \pm 184$ & $37,947 \pm 10,566$ & $29.3 \pm 3.3$ & $16 \pm 2.5$ & $16 \pm 4.9$ & $0.78 \pm 0.16$ & & $30,109 \pm 11,02$ \\
\hline prr9-1 & $19.6 \pm 1.8$ & $11.7 \pm 1.4$ & $12.8 \pm 2$ & $1.17 \pm 0.22$ & $3066 \pm 312$ & $31,486 \pm 4269$ & $20.4 \pm 2.3$ & $9.3 \pm 1.1$ & $3.7 \pm 1.2$ & $0.51 \pm 0.12$ & $1680 \pm 384$ & $23,899 \pm 3645$ \\
\hline$r d 26$ & $18.6 \pm 1.3$ & $10.9 \pm 1.1$ & $9.3 \pm 2.9$ & $0.85 \pm 0.15$ & $2088 \pm 282$ & $28,846 \pm 7409$ & $17.9 \pm 0.7$ & $9.7 \pm 1.1$ & $3.2 \pm 1.7$ & $0.36 \pm 0.15$ & $1391 \pm 303$ & $22,307 \pm 6800$ \\
\hline $\operatorname{sex} 1$ & $20.2 \pm 3.3$ & $9 \pm 1.6$ & $3.4 \pm 1.7$ & $0.47 \pm 0.13$ & $2342 \pm 341$ & $17,849 \pm 5304$ & $20.7 \pm 1.4$ & $8.6 \pm 1.5$ & $2 \pm 1.6$ & $0.25 \pm 0.13$ & $1744 \pm 54$ & $12,628 \pm 4161$ \\
\hline sid2 & $19.3 \pm 1$ & $10.6 \pm 0.9$ & $6.9 \pm 1.5$ & $0.75 \pm 0.09$ & $2051 \pm 228$ & $27,662 \pm 4195$ & $18.8 \pm 1$ & $9.7 \pm 0.9$ & $2.9 \pm 1$ & $0.3 \pm 0.09$ & $1496 \pm 233$ & $16,455 \pm 3529$ \\
\hline$t p t$ & $16.8 \pm 1$ & $9.4 \pm 0.7$ & $7.3 \pm 1.8$ & $0.92 \pm 0.18$ & $2331 \pm 475$ & $29,743 \pm 3442$ & $15.6 \pm 2.1$ & $8.2 \pm 1.9$ & $3 \pm 1.5$ & $0.41 \pm 0.1$ & $1498 \pm 251$ & $19,419 \pm 4703$ \\
\hline tre 1 & $18.8 \pm 1$ & $11 \pm 1.7$ & $9.5 \pm 2.6$ & $0.93 \pm 0.17$ & $2420 \pm 252$ & $32,195 \pm 7162$ & $17.7 \pm 0.8$ & $9.2 \pm 0.6$ & $3.4 \pm 0.8$ & $0.43 \pm 0.11$ & $1749 \pm 117$ & $21,960 \pm 2213$ \\
\hline TRE1-OE & $18 \pm 0.7$ & $10.9 \pm 1.1$ & $11 \pm 2.5$ & $1.08 \pm 0.19$ & $3305 \pm 173$ & $30,433 \pm 4743$ & \pm 1.1 & $10.1 \pm 0.9$ & $3.8 \pm 0.8$ & $0.45 \pm 0.07$ & $1894 \pm 54$ & $27,040 \pm 16,7$ \\
\hline
\end{tabular}

Values of genotypes that differ significantly from the values of Col-0 wild-type are noted in bold for each variable (ANOVAS and Tukey's post hoc tests results, $\mathrm{P}<0.05$ ). 
Changes in rosette leaf number were associated with modifications in the duration of rosette expansion in most genotypes: the longest was the duration of expansion, the highest was the rosette leaf number and reciprocally. Finally, in the genotypes analyzed here, the mean epidermal cell area in the 6th leaf was only slightly impacted by the mutations since only 6 mutants presented significant differences in cell area when compared to the wild-type. Mean epidermal cell area was decreased in all of them. Epidermal cell number in leaf 6 upper epidermis was significantly decreased in 15 mutants and increased in only one of them compared to the wild-type.

Soil water deficit caused a reduction in rosette area in all genotypes and it also reduced the variability in rosette area among the genotypes. In the soil water deficit condition, among the 35 mutants, 15 differed significantly from the wild-type for their rosette leaf area (Table 2). Two mutants, prr5-prr9 and etr1, showed a positive impact of the mutation on rosette leaf area whereas all others had a lower rosette area compared to the wild-type. This was related to a higher leaf number for etr 1 but a cumulative effect of higher leaf number and individual leaf area for prr5-prr9 when compared to their wild-type grown in the same condition. The reduction of 20 to 15 mutants with significant variation of rosette leaf area between well-watered and water deficit conditions, respectively, was mainly due to a reduction of the number of mutants with significant changes in their individual leaf areas since the mutants with different leaf number were the same under the two water regimes except one mutant (tpt). In the soil water deficit condition, the cellular variables were also less modified by the mutations since 7 and 9 mutants had different mean cell area and cell number, respectively, when compared to the wild-type. Cell area and/or cell number were decreased in these mutants compared to the wild- type.

\subsection{The Leaf Growth Response to the Drought Treatment Depends on the Genotype}

The statistical analysis of the genotypic (G) and environmental (E) effects on growth variables from cell to rosette scale revealed a predominant effect of the genotype on most variables (from $36 \%$ to $66 \%$ of variance explained depending on the considered variable, Table 3).

Only, for individual leaf 6 area and mean cell area, the genotype and environment effects were comparable (from $36 \%$ to $38 \%$ of the variance). The effect of environmental variability was significant for all variables except for the duration of growth (from $7 \%$ to $38 \%$ of variance explained depending on the considered variables). A significant interaction between the 2 factors was found also for all the variables (from 5\% to $10 \%$ of the variance explained) underlining that the variability of response to the water deficit depended on the genotype (Table 3). This $\mathrm{G} \times \mathrm{E}$ interaction was explored deeper by comparing the percentage of variation of each variable between the well-watered and water deficit conditions for each genotype (Figure 1). The duration of rosette expansion was not affected by the water deficit treatment in most genotypes (a variation less than $10 \%$, Figure 1 ). Only 4 mutants showed an increase in the duration of growth (between 10 and $40 \%$ of variation). The main variations with soil water deficit were observed for individual leaf area and rosette leaf area (Figure 1). These variables were decreased by $10 \%$ to $80 \%$ depending on the mutants. As the ANOVA revealed a significant $\mathrm{G} \times \mathrm{E}$ interaction, the variation of growth caused by the soil water deficit was also compared between mutants through a hierarchical clustering analysis (Figure 1).

Table 3. Analysis of the leaf growth variability among 36 genotypes grown under two contrasted soil water contents $(0.4$ and $0.23 \mathrm{~g} \cdot \mathrm{H}_{2} \mathrm{O} \cdot \mathrm{g}^{-1}$ dry soil, respectively) by ANOVA. The percentages of variance explained are indicated for each factor (genotype and soil water content, respectively) and for their interaction (genotype $\times$ soil water content).

\begin{tabular}{|c|c|c|c|c|}
\hline \multirow[b]{2}{*}{ Growth traits } & \multicolumn{4}{|c|}{ Factors } \\
\hline & Genotype & Soil water content & Genotype $\times$ soil water content & Total model \\
\hline Duration of expansion & $65.6^{* * *}$ & $0.01 \mathrm{~ns}$ & $7.8^{* * *}$ & 73.4 \\
\hline Leaf number & $65.9^{* * *}$ & $7.0^{* * *}$ & $4.6^{* * *}$ & 77.5 \\
\hline Rosette area & $55.2^{* * *}$ & $21.3^{* * *}$ & $9.8^{* * *}$ & 86.3 \\
\hline Leaf 6 area & $36.7^{* * *}$ & $38.1^{* * *}$ & $7.8^{* * *}$ & 82.6 \\
\hline Cell area & $35.7^{* * *}$ & $37.3^{* * *}$ & $9.2^{* * *}$ & 82.2 \\
\hline Cell number & $43.8^{* * *}$ & $18.4^{* * *}$ & $8.2^{* * *}$ & 70.4 \\
\hline
\end{tabular}

The level of significance (ns: $\mathrm{P}>0.05 ;{ }^{* * *}: \mathrm{P}<0.001$ ) are indicated for each factor and each growth trait. 


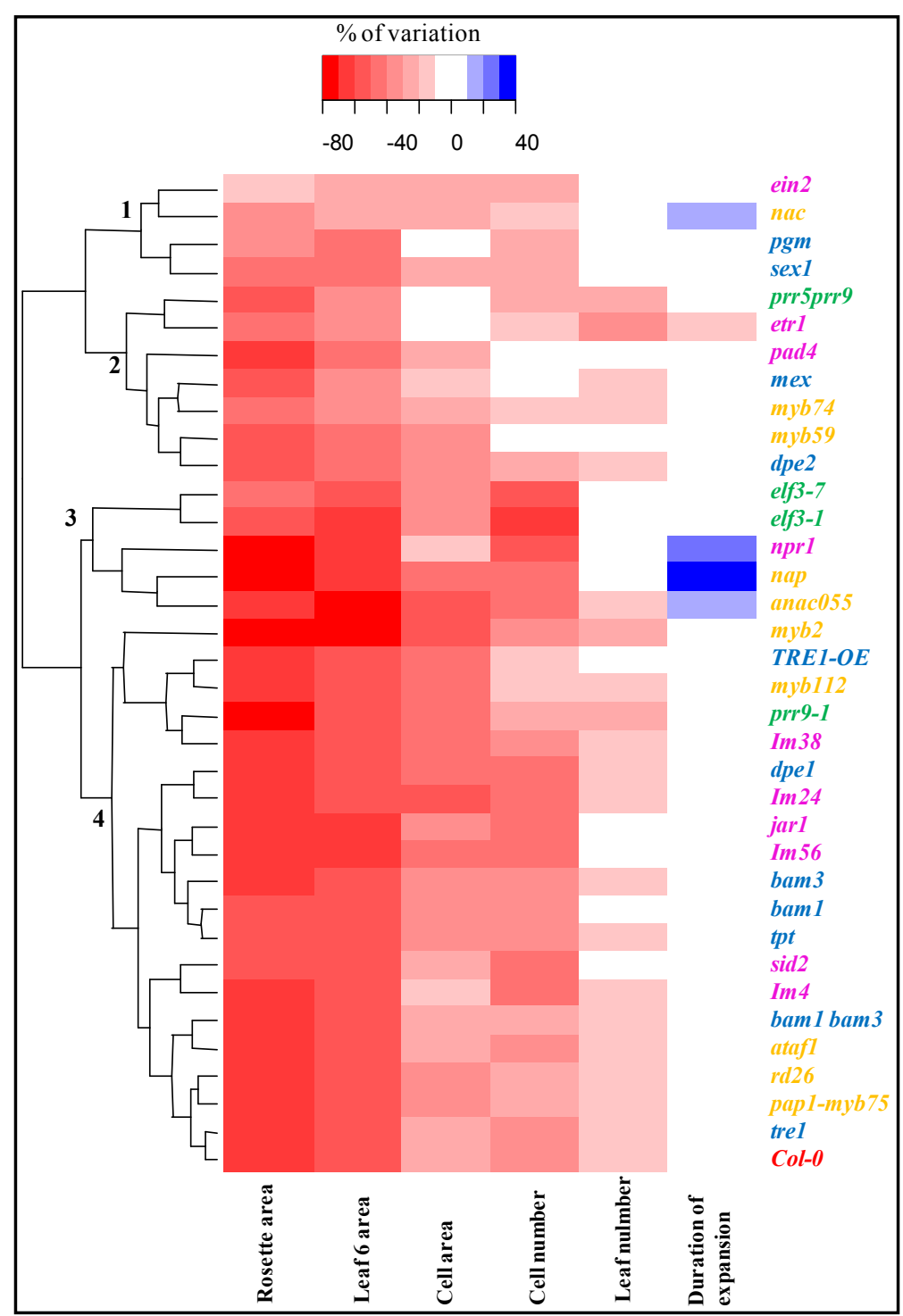

Figure 1. Overlay heat map showing the percentage of variation of six leaf growth variables under water stress in comparison to the value under the well-watered condition in 36 Arabidopsis thaliana genotypes. The six leaf growth variables are (from left to right): rosette area, leaf 6 area, cell area in the upper epidermis of leaf 6 , cell number in the upper epidermis of leaf 6 , number of rosette leaves, and duration of rosette expansion. The percentage of variation is represented by a color, with closeness to blue indicating an increase of the value of the variable by the soil water deficit and closeness to red reveals a decrease of the value by the water deficit treatment (the numerical scale is given on the top of the figure). The dendrogram on the left represents the proximity between the response of each variable, as calculated from a hierarchical clustering analysis using Euclidean distance and reveals 4 groups. Mutants modified in the same function are noted with the same color (in red: the wild-type; in green: the circadian clock mutants; in blue: the carbon mutants; in orange: the transcription factors mutants and in pink: the signal mutants).

Four significant different groups of mutants were distinguished by this analysis with a mixture of mutants from the various functional pathways in each group. The Col-0 wild-type belonged to the 4th group, the group with the higher number of genotypes, revealing a similar impact of the water deficit in the wild-type than in a large proportion of mutants (Figure 1). The two most distant groups from this 4th group were the groups 1 and 2 which contained 4 and 7 mutants, respectively. The mean values of leaf growth duration of the genotypes of these 4 groups revealed maximal distant values between groups 2 and 3 with 21.3 and 14.6 days, respectively whereas groups 1 and 4 presented similar values with 19.4 and 18.7 days, respectively. These groups did not al- 
low identifying mutants with functional pathways specifically affected by the water deficit.

A principal component analysis (PCA) was performed in order to explore the multivariate impact of the soil water deficit treatment on the studied variables and try to identify the specific growth properties of each of the 4 groups revealed in the clustering analysis (Figure 2).

First and second components explained $64 \%$ and $24 \%$ of the total variance, respectively (Figure $2 \mathrm{~A}$ ). The projection of the variables in the first factorial plan showed a good representation of all variables (Figure 2A). The duration of rosette expansion contributed more to PC1 whereas leaf expansion contributed more to PC2. The projection of the genotypes in the first factorial plan with water regime as a factor revealed a significant discrimination of the two water treatments in this plan (Figure 2B). The discrimination between treatments was overall observed along the second axis, i.e., confirming the absence of impact of the soil water deficit on the duration of expansion in this set of genotypes (Figure 2B). The projection of the mutants in the first factorial plan using the four dendrogram groups as factor also revealed a significant discrimination between some of the groups (Figure 1, Figure 2C, $\mathrm{P}=0.013$ ). Discrimination between groups 2 and 3 was observed along both axes as also confirmed by the distance between these two groups in the clustering analysis (Figure 1, Figure 2C). However, the separation between groups 1 and 4 observed in the clustering analysis was not confirmed in the first factorial plan of the PCA (Figure 2C). The high genotypic variability revealed by the distance of the mutants from the centroid of each treatment or group makes difficult to separate the groups.

\subsection{Plasticity of Leaf Growth Variables in Response to a Moderate Soil Water Deficit Depends on the Duration of Rosette Expansion}

We explored the relationships between the 6 leaf growth variables measured on the genotypes grown in the wellwatered condition and the same leaf growth variables measured on the same genotypes grown in the moderate soil water deficit treatment. All 6 correlations were significant with higher correlation coefficient for the variables at the most integrated scale (Figures 3A-D) than at the cellular scale (Figure 3E and Figure 3F). These relationships revealed an absence of deviance from the 1:1 line for the duration of growth whereas all the other variables showed a decrease of the variable under soil water deficit compared to the well-watered condition. This deviation from the 1:1 line was particularly strong for genotypes with large rosette area (Figure 3C). The mutants with the largest rosettes have been more impacted by the water deficit than those with the smallest rosette areas.

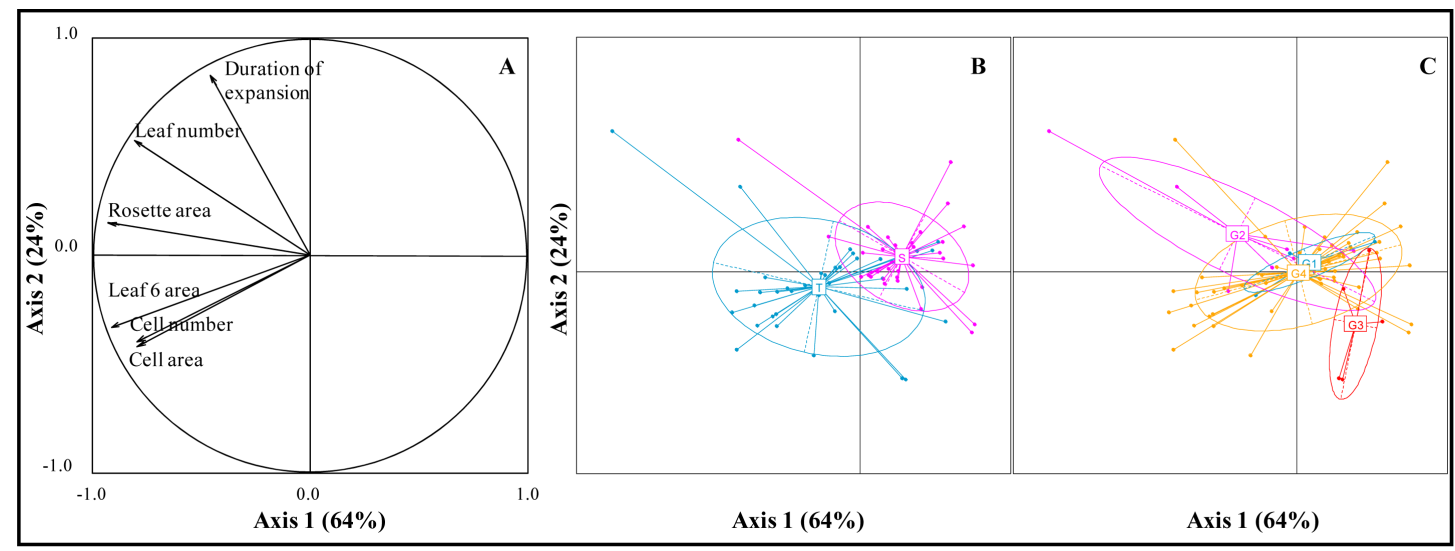

Figure 2. Principal component analysis on rosette growth variables measured on 36 Arabidopsis thaliana genotypes grown under well-watered $(\mathrm{T})$ and water deficit conditions (S). Only the first two axes are shown. A Representation of the variables; duration of rosette expansion, number of rosette leaves, leaf 6 area, cell number in leaf 6 upper epidermis and cell area in leaf 6 upper epidermis; B Representation of the genotypes with centers of gravity and lines connected to each genotype shown for each condition, T, in blue and S, in pink; C Representation of the genotypes with centers of gravity and lines connected to each genotype shown for each group, G1 to G4 (G1: in blue; G2: in pink; G3: in red; G4: in orange), defined by the dendrogram presented in Figure 1. Ellipses represent inertia ellipses of each group. Each inertia ellipse is centered on the means, its width and height are given by 1.5 times the standard deviation of the coordinates on axes, and the covariance sets the slope of the main axis. 

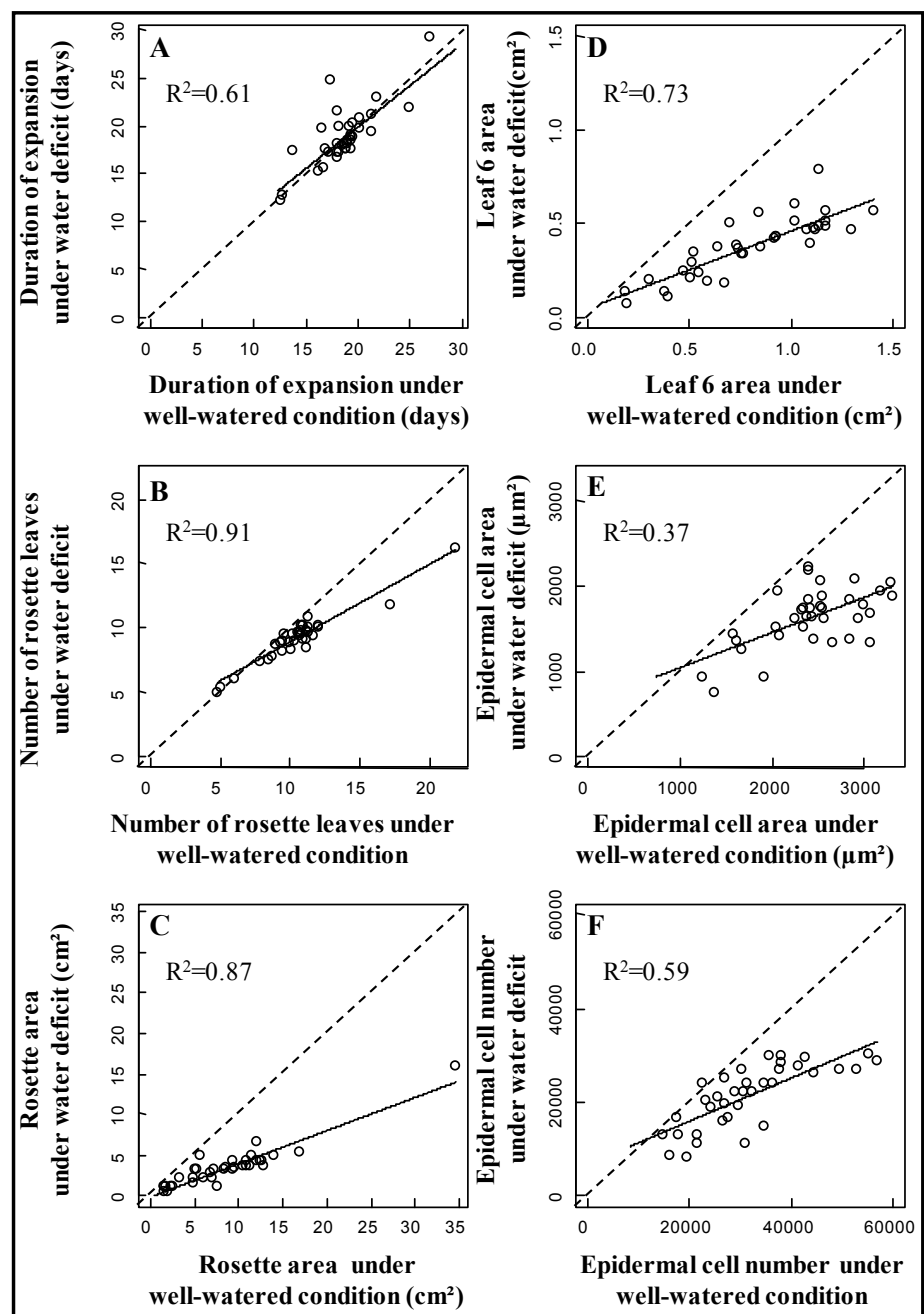

Figure 3. Relationships between mean values of rosette growth variables for the 36 Arabidopsis thaliana genotypes under well-watered and moderate soil water deficit conditions. The six leaf growth variables are the duration of rosette expansion $\mathbf{A}$; the number of rosette leaves $\mathbf{B}$; final rosette area $\mathbf{C}$; leaf 6 area $\mathbf{D}$; mean cell area in leaf 6 upper epidermis $\mathbf{E}$; mean cell number in leaf 6 upper epidermis $\mathbf{F}$. The dashed line represents the 1:1 ratio.

We further explored the relationships between the plasticity of leaf growth variables in response to moderate soil water deficit and the duration of rosette expansion of the same genotypes in the well-watered condition (Figure 4). The response of leaf 6 area to the soil water deficit treatment was positively correlated to the duration of rosette expansion in the well-watered condition suggesting that late flowering genotypes could have a proportionate advantage under water shortage at the individual leaf scale (Figure 4B). In contrast, the response of leaf number to the soil water deficit treatment was negatively correlated to the duration of rosette expansion in well-watered condition (Figure 4A). These two correlations were inversed, and there was no significant correlation between the duration of rosette expansion and the whole rosette leaf area suggesting that all leaves of the rosette responded similarly than the 6th leaf to the water deficit scenario (Figure 4C).

\section{Discussion}

\subsection{Genetic Variability of Leaf Growth and Its Response to Drought}

Reducing leaf expansion is a common response of plants for drought acclimation, diminishing evaporative leaf surface area and improving water status at the whole plant level. Optimal plant acclimation is reported for geno- 


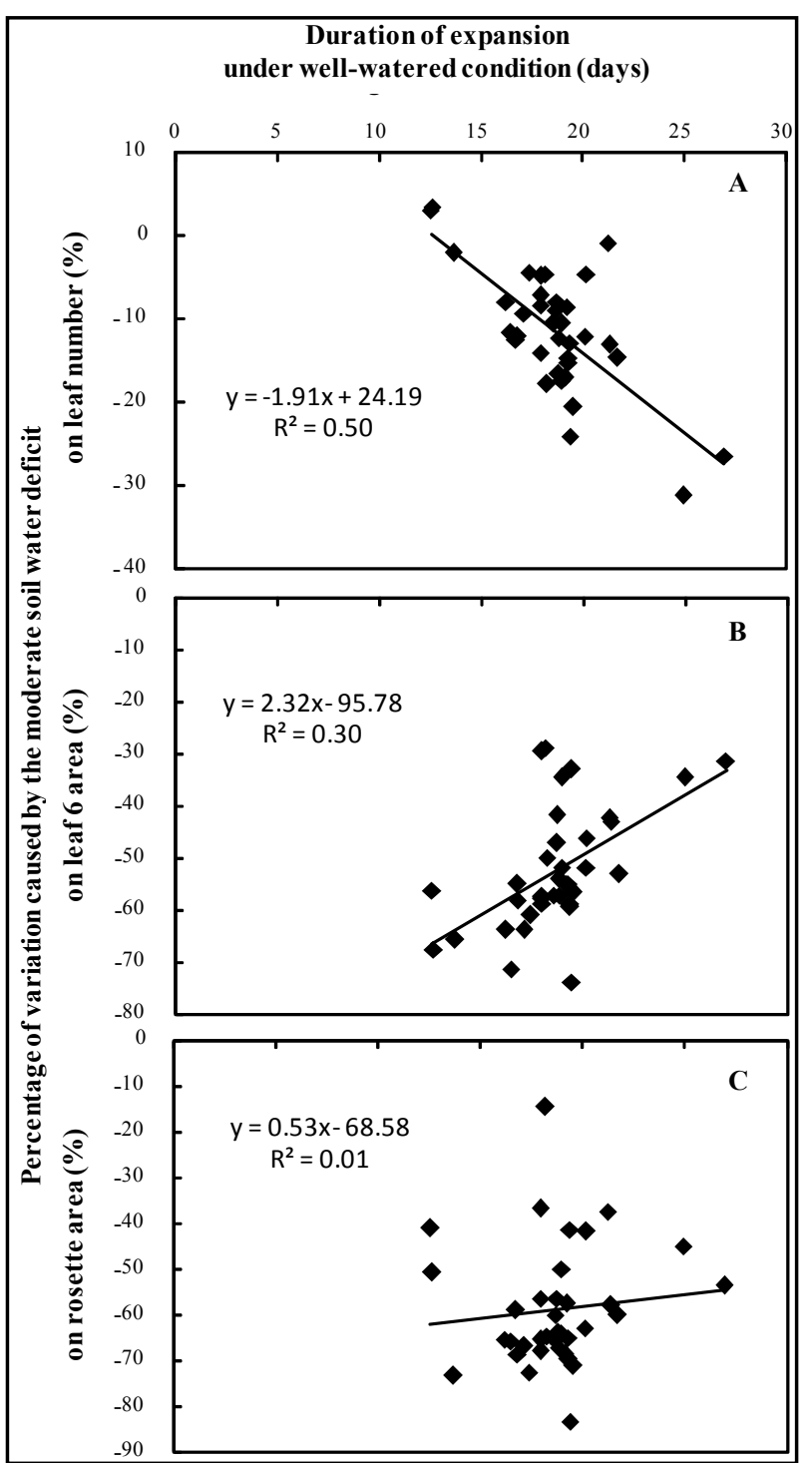

Figure 4. Relationships between the duration of rosette expansion in well-watered condition and the percentage of variation of three growth variables when the same plants are subjected to the moderate soil water deficit treatment. Growth variables are the number of rosette leaves A, leaf 6 area $\mathbf{B}$ and rosette area $\mathbf{C}$.

types able to minimize the trade-off between growth and water loss [29]. The 35 Arabidopsis thaliana mutants selected in this work were chosen because they had been shown to be impaired in functional pathways that could interact with this trade-off either via modulation of transcription factors [30], carbon metabolism [31] [32], circadian clock [33] or signal transduction [34]. Leaf growth variability among mutants and in comparison to their common wild-type was measured at different scales and under two water regimes. Ranking of the genotypes according to their leaf growth variables depended on the considered scale and on the environmental conditions. Despite drastic changes in their physiological, biochemical and/or molecular phenotypes described earlier, final rosette areas differ from that of the wild-type in 57\% of them in the well-watered condition and $43 \%$ of them in the water deficit condition. Whole rosette area was reduced in response to the soil water deficit condition in all genotypes but the extent of this response differed among them. This first result suggests genetic differences in acclimation capacities to drought. The question is to understand what could be the source of this variability? We wondered if these differences of behavior in response to drought could be partially due to differences of flower- 
ing time as suggested by some other studies [13] [18] [19]. We addressed this question by conducting a holistic approach comparing the relationship between growth related variables that may allow us to reveal emergent properties that are not visible when we look at the behavior of one genotype.

\subsection{How Growth Duration Does Impact Growth Variables?}

Whereas flowering time is known to be a highly plastic trait in response to the environment (day-length, cold, drought [35]), the mild water deficit imposed to the set of genotypes selected in the present study did not lead to modification of growth duration in most genotypes. This could be due to the long day conditions in which plants were grown. A recent analysis of the effect of water deficit on individual leaf growth in 3-dimensions revealed that the increase in duration of expansion caused by water deficit is not observed in long days, i.e. when flowering occurs rapidly and the number of leaves per plant is low [36]. We can suppose that the plant development cycle is so fast that plants have not time to implement an adaptive strategy to face drought. Although our experimental conditions (long days) were favorable to early flowering, few mutants flowered significantly later than the wild-type and consequently they also had a higher total number of leaves in rosettes than the wild-type. The range of variation in duration of growth was even large among mutants (between 12 and 27 days under well watered conditions) suggesting the high genetic plasticity of flowering time underlined in [35]. This variability allowed us exploring the impact of the flowering time on the relative response of leaf number, leaf area and rosette area to drought as discussed below.

In many studies, the effects of environmental conditions on leaf production and leaf expansion are analyzed through the effects on the number of leaves as an indicator of leaf production, and the area of a leaf at a given nodal position as an indicator of individual leaf expansion [9] [37] [38]. Similarly, the variation in leaf expansion among different genotypes is analyzed by comparing leaf area of a given leaf at a specific rank on the plant (the sixth leaf of 200 genotypes in [39]). This leads to a bias when individual leaf expansion is compared in genotypes with different number of rosette leaves because part of individual leaf expansion at each position depends on the number of leaves produced by the plant strongly linked to whole plant cycle duration. Results presented here show that the analysis is even more complicated as the relationship between individual leaf area at a nodal position and the number of rosette leaves is not stable and is affected by environmental conditions such as soil water deficit.

In the well-watered condition, leaf area at a given nodal position is higher for plants with a reduced number of leaves as shown for a given genotype grown at different day-lengths: increasing day-length reduces the number of rosette leaves and also causes an increase in individual leaf area at a given nodal position [20]. This shows close relationship between whole plant vegetative growth duration and individual leaf expansion. It is well-established that moderate soil water deficits reduce final individual leaf areas [8] [9] [36] and this is confirmed here in the whole set of genotypes. However, we showed that the moderate water deficit affected differently the leaf area among mutants according to their duration of rosette development. Figure 3 showed that the rosette area was less modified by water deficit in the mutants with small rosette leaf area than in the ones with large rosette area. This difference of drought impact can be due to the fact that the early flowering mutants were subjected to the stress treatment during a shorter period than the late flowering ones. However the results recently presented in [19] showed contradictory results in near isogenic lines underlining higher capacities of drought acclimation in late flowering lines than in early flowering ones. The late flowering lines, i.e. the ones with duration of vegetative growth higher than the threshold time of 40 days after sowing, were able to recover their growth in the second half of their vegetative development by growing faster in water deficit than in well watered condition. In our conditions, under long day-length, all the mutants showed duration of vegetative growth lower than this threshold time of 40 days. A higher reduction in the leaf number was observed in the late flowering mutants than in the early flowering mutants. Contrastingly, the individual leaf areas were more affected by the water deficit treatment in early flowering mutants whereas late flowering mutants better maintained individual leaf areas (Figure 4).

\subsection{Role of Flowering Time in the Drought Response Strategy of Plants}

A study has shown the pleiotropic effects of flowering genes such as FRIGIDA on flowering time and shoot growth rate [24]. Our study revealed that a lot of genes have also this pleiotropic effect since various mutants showed both variations in leaf growth and flowering time in comparison to the wild-type. We also showed that 
this pleiotropic effect was dependent of the soil water content underlining the complementary role of growth and flowering in the plant adaptation to drought.

The type of drought response strategy developed by plants is largely dependent of the drought intensity, duration and period of application but depends also on species or genotypes. A common modification observed in the plant stress response is a lengthening of the life cycle, delaying the transition from vegetative to reproductive phase. A delay of flowering time by a stress has been reported for Arabidopsis thaliana in response to various stresses such as shade [40], phosphorous deficiency [41], drought [42] or biotic interactions [43]. It has been suggested that this delay in flowering would allow plant to maximize resources and ensure a successful reproduction [5] [41]. The analysis of the set of genotypes presented here shows that the most important differences in rosette leaf area between mutants and wild-type is observed when mutants have significant differences in leaf number due to different vegetative growth duration. This result confirms the preponderant impact of the vegetative growth duration in the biomass production. This strategy of delaying flowering time was also described as a mean for plants to compensate partially for the leaf expansion decrease by drought since this lengthening of the vegetative phase is accompanied by a more important leaf production. For years, big plants were searched in crops to increase potential productivity since the late flowering plants have a longer cycle duration and consequently higher biomass. However the results presented here bring new insight into this strategy. Our holistic approach comparing 36 genotypes under similar growth conditions revealed a strong negative impact of plant size in their response to drought (Figure 3). The mutants with the biggest rosettes seem to have been more largely impacted by the water deficit than the smallest as already observed in Arabidopsis [44] and Centaurea [45] suggesting that a longer vegetative phase may be a disadvantage to resist to drought. This result underlines an intriguing paradox. Whereas the lengthening of plant development delaying the flowering time was described, for long time, as a potential adaptative strategy in response to drought, our analysis shows a negative impact of late flowering time in the response of plant growth to drought. This conclusion is consistent with a recent study which reported that higher fitness was associated with earlier bolting, greater early allocation to increased number of inflorescences [46]. They showed that the bolting date and the inflorescence mass were the most important determinants of the plant fitness: The more a plant invests time and mass in reproduction, the better its fitness is. This early reproduction also allows continuing carbon acquisition as inflorescences contribute significantly to the Arabidopsis plant carbon gain during its life time [47]. The plasticity of flowering time response to drought between genotypes would be an important component of the plant fitness [5] and flowering would be involved in the local adaptation of plants [48]. Our analysis revealed also a more complex role of growth duration in the drought response strategy. An opposite impact of flowering time was observed on the response of two growth variables to drought, leaf number and leaf expansion. Interestingly, the early-flowering mutants, i.e. the ones with short growth duration, presented a lower decrease of leaf number but a stronger decrease of the individual leaf area expansion than the late-flowering ones. This tendency is consistent with the growth results observed in the interaction between day-length and drought in Arabidopsis. The number of leaves is more affected by drought in plants with a long vegetative cycle (grown in short days), than plants with a short vegetative cycle [36] (grown in long days). However these results are discordant with previous observations on Near Inbred Lines (NILS) issued from the Landsberg erecta $\mathrm{x}$ Antwerp-1 population which showed an adaptative strategy to drought in the late flowering NILS allowing them a better shoot growth under mild water deficit than the early flowering ones [19].

\section{Conclusion}

The analysis of the genetic variability of leaf growth related variables in response to drought showed a preponderant impact of flowering time on the response of some traits. The variability of flowering time among genotypes suggested that the late development of reproductive organs in the life cycle could be a disadvantage for annual plants to resist or adapt to water deficit. Although some studies use the flowering time as an estimator of the level of the drought escape strategy between well watered and water deficit conditions [49], we suggest here that a modification of flowering time will not only be a consequence of drought, but also be a determining process explaining at least a part of the leaf response to drought. Although some studies such as ours suggest that early flowering time can be an advantage in terms of water saving or carbon gain in response to drought, we open the question why plants lengthen the vegetative phase under drought when grown under a short day length? 


\section{Acknowledgements}

We are grateful to all people who have shared their genotypes for this study: Vicky Buchanon-Wollaston, Mark Stitt, Sam Zeeman, Laurence Lejay and Fabrice Varoquaux (see Table 1). This work was supported by AgronOmics, a European sixth framework integrated project (LSHG-CT-2006-037704) and a grant from the Interuniversity Attraction Poles Programme (IUAP VI/33), initiated by the Belgian State, Science Policy Office. The UMR EEF is supported by the French National Research Agency through the Laboratory of Excellence ARBRE (ANR-12- LABXARBRE-01). The funders had no role in study design, data collection and analysis, decision to publish, or preparation of the manuscript.

\section{References}

[1] Bray, E.A. (1997) Plant Responses to Water Deficit. Trends in Plant Science, 2, 48-54.

[2] Skirycz, A. and Inze, D. (2010) More from Less: Plant Growth under Limited Water. Current Opinion in Biotechnology, 21, 197-203. http://dx.doi.org/10.1016/j.copbio.2010.03.002

[3] Tardieu, F., Granier, C. and Muller, B. (2011) Water Deficit and Growth. Co-Ordinating Processes without an Orchestrator? Current Opinion in Plant Biology, 14, 283-289. http://dx.doi.org/10.1016/j.pbi.2011.02.002

[4] Grime, J. (1977) Evidence for Existence of Three Primary Strategies in Plants and Its Relevance to Ecological and Evolutionary Theory. American Naturalist, 111, 1169-1194.

[5] McKay, J.K., Richards, J.H. and Mitchell-Olds, T. (2003) Genetics of Drought Adaptation in Arabidopsis thaliana : I. Pleiotropy Contributes to Genetic Correlations among Ecological Traits. Molecular Ecology, 12, 1137-1151. http://dx.doi.org/10.1046/j.1365-294X.2003.01833.x

[6] Franck, N., Winkler, S., Pastenes, C. and Infante, R. (2007) Acclimation to Sun and Shade of Three Accessions of the Chilean Native Berry-Crop Murta. Agroforestry Systems, 69, 215-229. http://dx.doi.org/10.1007/s10457-007-9040-2

[7] Verslues, P.E. and Juenger, T.E. (2011) Drought, Metabolites, and Arabidopsis Natural Variation: A Promising Combination for Understanding Adaptation to Water-Limited Environments. Current Opinion in Plant Biology, 14, 240245. http://dx.doi.org/10.1016/j.pbi.2011.04.006

[8] Baerenfaller, K., Massonnet, C., Walsh, S., Baginsky, S., Buhlmann, P., Hennig, L., Hirsch-Hoffmann, M., Howell, KA., Kahlau, S., Radziejwoski, A., Russenberger, D., Rutishauser, D., Small, I., Stekhoven, D., Sulpice, R., Svozil, J., Wuyts, N., Stitt, M., Hilson, P., Granier, C. and Gruissem, W. (2012) Systems-Based Analysis of Arabidopsis Leaf Growth Reveals Adaptation to Water Deficit. Molecular Systems Biology, 8, 1-18.

http://dx.doi.org/10.1038/msb.2012.39

[9] Aguirrezabal, L., Bouchier-Combaud, S., Radziejwoski, A., Dauzat, M., Cookson, S.J. and Granier, C. (2006) Plasticity to Soil Water Deficit in Arabidopsis thaliana: Dissection of Leaf Development into Underlying Growth Dynamic and Cellular Variables Reveals Invisible Phenotypes. Plant, Cell and Environment, 29, 2216-2227. http://dx.doi.org/10.1111/j.1365-3040.2006.01595.x

[10] Hummel, I., Pantin, F., Sulpice, R., Piques, M., Rolland, G., Dauzat, M., Christophe, A., Pervent., M., Bouteille, M., Stitt, M., Gibon, Y. and Muller, B. (2010) Arabidopsis Plants Acclimate to Water Deficit at Low Cost through Changes of Carbon Usage: An Integrated Perspective Using Grdwth, Metabolite, Enzyme, and Gene Expression Analysis. Plant Physiology, 154, 357-372. http://dx.doi.org/10.1104/pp.110.157008

[11] Bray, E.A. (2004) Genes Commonly Regulated by Water-Deficit Stress in Arabidopsis thaliana. Journal of Experimental Botany, 55, 2331-2341. http://dx.doi.org/10.1093/jxb/erh270

[12] Claeys, H., De Bodt, S. and Inze, D. (2014) Gibberellins and DELLAs: Central Nodes in Growth Regulatory Networks. Trends in Plant Science, 19, 231-239. http://dx.doi.org/10.1016/j.tplants.2013.10.001

[13] Granier, C., Aguirrezabal, L., Chenu, K., Cookson, S.J., Dauzat, M., Hamard, P., Thioux, J.J., Rolland, G., BouchierCombaud, S., Lebaudy, A., Muller, B., Simonneau, T. and Tardieu, F. (2006) PHENOPSIS, an Automated Platform for Reproducible Phenotyping of Plant Responses to Soil Water Deficit in Arabidopsis thaliana Permitted the Identification of an Accession with Low Sensitivity to Soil Water Deficit. New Phytologist, 169, 623-635. http://dx.doi.org/10.1111/j.1469-8137.2005.01609.x

[14] Bouchabke-Coussa, O., Quashie, M.L., Seoane-Redondo, J., Fortabat, M.N., Gery, C., Yu, A., Linderme, D., Trouverie, J., Granier, F., Teoule, E. and Durand-Tardif, M. (2008) ESKIMO1 Is a Key Gene Involved in Water Economy as Well as Cold Acclimation and Salt Tolerance. BMC Plant Biology, 8, 125. http://dx.doi.org/10.1186/1471-2229-8-125

[15] Koorneef, M., Hanhart, C.J. and van der Veen, J.H. (1991) A Genetic and Physiological Analysis of Late Flowering Mutants in Arabidopsis thaliana. Molecular and General Genetics, 229, 57-66. http://dx.doi.org/10.1007/BF00264213

[16] Hausmann, N.J., Juenger, T.E., Sen, S., Stowe, K.A., Dawson, T.E. and Simms, A.L. (2005) Quantitative Trait Loci 
Affecting $\delta^{13} \mathrm{C}$ and Response to Differential Water Availability in Arabidopsis thaliana. Evolution, 59, 81-96. http://dx.doi.org/10.1554/04-104

[17] McKay, J.K., Richards, J.H. and Nemali, K.S. (2008) Genetics of Drought Adaptation in Arabidopsis thaliana. II. QTL Analysis of a New Mapping Population, KAS-1 × TSU-1. Evolution, 62, 3014-3026. http://dx.doi.org/10.1111/j.1558-5646.2008.00474.x

[18] Tisne, S., Schmalenbach, I., Reymond, M., Dauzat, M., Pervent, M., Vile, D. and Granier, C. (2010) Keep on Growing under Drought: Genetic and Developmental Bases of the Response of Rosette Area Using a Recombinant Inbred Line Population. Plant, Cell and Environment, 33, 1875-1887. http://dx.doi.org/10.1111/j.1365-3040.2010.02191.x

[19] Schmalenbach, I., Zhang, L., Reymond, M. and Jiménez-Gómez, J.M. (2014) The Relationship between Flowering Time and Growth Responses to Drought in the Arabidopsis Landsberg erecta x Antwerp-1 Population. Frontiers in Plant Science, 5, 609. http://dx.doi.org/10.3389/fpls.2014.00609

[20] Cookson, S.J., Chenu, K. and Granier, C. (2007) Day-Length Affects the Dynamics of Leaf Expansion and Cellular Development in Arabidopsis thaliana Partially through Floral Transition Timing. Annals of Botany, 99, 703-711. http://dx.doi.org/10.1093/aob/mcm005

[21] Alonso-Blanco, C., El-Assal, S.E.D., Coupland, G. and Koornneef, M. (1998) Analysis of Natural Allelic Variation at Flowering Time Loci in the Landsberg erecta and Cap Verde Islands Ecotypes of Arabidopsis thaliana. Genetics, 149, 749-764.

[22] Juenger, T.E., McKay, J.K., Hausmann, N., Keurentjes, J.J.B., Saunak, S., Stowe, K.A., Dawson, T.E., Simms, E.L. and Richards, J.H. (2005) Identification and Characterization of QTL Underlying Whole-Plant Physiology in Arabidopsis thaliana: $\delta^{13} \mathrm{C}$, Stomatal Conductance and Transpiration Efficiency. Plant, Cell and Environment, 28, 697-708. http://dx.doi.org/10.1111/j.1365-3040.2004.01313.x

[23] El-Lithy, M.E., Bentsink, L., Hanhart, C.J., Ruys, G.J., Rovito, D., Broekhof, J.L.M., van der Poel, H.J.A., van Eijk, M.T.J., Vreugdenhil, D. and Koornneef, M. (2006) New Arabidopsis Recombinant Inbred Line Populations Genotyped Using SNPWave and Their Use for Mapping Flowering-Time Quantitative Trait Loci. Genetics, 172, 1867-1876. http://dx.doi.org/10.1534/genetics.105.050617

[24] Lovell, J.T., Juenger, T.E., Michaels, S.D., Lasky, J.R., Platt, A., Richards, J.H., Yu, X., Easlon, H.M., Sen, S. and McKay, J.K. (2013) Pleiotropy of FRIGIDA Enhances the Potential for Multivariate Adaptation. Proceedings of Royal Society B, 280, Article ID: 20131043. http://dx.doi.org/10.1098/rspb.2013.1043

[25] Shindo, C., Aranzana, M.J., Lister, C., Baxter, C., Nicholls, C., Nordborg, M. and Dean, C. (2005) Role of FRIGIDA and FLOWERING LOCUS C in Determining Variation in Flowering Time of Arabidopsis. Plant Physiology, 138, 1163-1173. http://dx.doi.org/10.1104/pp.105.061309

[26] Fabre, J., Dauzat, M., Nègre, V., Wuyts, N., Tireau, A., Gennari, E., Neveu, P., Tisné, S., Massonnet, C., Hummel, I. and Granier, C. (2011) PHENOPSIS DB: An Information System for Arabidopsis thaliana Phenotypic Data in an Environmental Context. BMC Plant Biology, 11, 77. http://dx.doi.org/10.1186/1471-2229-11-77

[27] Boyes, D.C., Zayed, M.A., Ascenzi, R., McCaskill, A.J., Hoffman, N.E., Davis, K.R. and Görlach, J. (2001) Growth Stage-Based Phenotypic Analysis of Arabidopsis a Model for High Throughput Functional Genomics in Plants. Plant Cell, 13, 1499-1510. http://dx.doi.org/doi:10.1105/TPC.010011

[28] R Development Core Team (2007) R: A Language and Environment for Statistical Computing. R Foundation for Statistical Computing, Vienna. http://www.R-project.org

[29] Dudley, S.A. (1996) Differing Selection on Plant Physiological Traits in Response to Environmental Water Availability: A Test of Adaptive Hypotheses. Evolution, 50, 92-102. http://dx.doi.org/10.2307/2410783

[30] Singh, K.B., Foley, R.C. and Onate-Sanchez, L. (2002) Transcription Factors in Plant Defense and Stress Responses. Current Opinion in Plant Biology, 5, 430-436. http://dx.doi.org/10.1016/S1369-5266(02)00289-3

[31] Pantin, F., Simonneau, T., Rolland, G., Dauzat, M. and Muller, B. (2011) Control of Leaf Expansion: A Developmental Switch from Metabolics to Hydraulics. Plant Physiology, 156, 803-815. http://dx.doi.org/10.1104/pp.111.176289

[32] Pantin, F., Fanciullino, A.L., Massonnet, C., Dauzat, M., Simonneau, T. and Muller, B. (2014) Buffering Growth Variations against Water Deficits through Timely Carbon Usage. Frontiers in Plant Science, 4, 483. http://dx.doi.org/10.3389/fpls.2013.00483

[33] Sanchez, A., Shin, J. and Davis, S.J. (2011) Plant Signaling and Behavior, 6, 223-231. http://dx.doi.org/10.4161/psb.6.2.14893

[34] Shinozaki, K. and Yamaguchi-Shinozaki, K. (2007) Gene Networks Involved in Drought Stress Response and Tolerance. Journal of Experimental Botany, 58, 221-227. http://dx.doi.org/10.1093/jxb/erl164

[35] Koornneef, M., Alonso-Blanco, C. and Vreugdenhil, D. (2004) Naturally Occurring Genetic Variation in Arabidopsis thaliana. Annual Review of Plant Biology, 55, 141-172. http://dx.doi.org/10.1146/annurev.arplant.55.031903.141605 
[36] Wuyts, N., Massonnet, C., Dauzat, M. and Granier, C. (2012) Structural Assessment of the Impact of Environmental Constraints on Arabidopsis thaliana Leaf Growth: A 3D Approach. Plant Cell and Environment, 35, 1631-1646. http://dx.doi.org/10.1111/j.1365-3040.2012.02514.x

[37] Yegappan, T.M., Paton, D.M., Gates, C.T. and Muller, W.J. (1980) Water Stress in Sunflower (Helianthus annuus L.). I. Effect on Plant Development. Annals of Botany, 46, 61-70.

[38] Yegappan, T.M., Paton, D.M., Gates, C.T. and Muller, W.J. (1982) Water Stress in Sunflower (Helianthus annuus L.). II. Effects on Leaf Cells and Leaf Area. Annals of Botany, 49, 63-68.

[39] Massonnet, C., Tisné, S., Radziejwoski, A., Vile, D., De Veylder, L., Dauzat, M. and Granier, C. (2011) New Insights into the Control of Endoreduplication: Endoreduplication Could Be Driven by Organ Growth in Arabidopsis Leaves. Plant Physiology, 157, 2044-2055. http://dx.doi.org/10.1104/pp.111.179382

[40] Dorn, L.A., Pyle, E.H. and Schmitt, J. (2000) Plasticity to Light Cues and Resources in Arabidopsis thaliana: Testing for Adaptive Value and Costs. Evolution, 54, 1982-1994. http://dx.doi.org/10.1111/j.0014-3820.2000.tb01242.x

[41] Nord, E.A. and Lynch, J.P. (2008) Delayed Reproduction in Arabidopsis thaliana Improves Fitness in Soil with Suboptimal Phosphorus Availability. Plant, Cell and Environment, 31, 1432-1441. http://dx.doi.org/10.1111/j.1365-3040.2008.01857.x

[42] Comont, D., Winters, A. and Gwynn-Jones, D. (2012) Acclimation and Interaction between Drought and Elevated UV-B in A. thaliana: Differences in Response over Treatment, Recovery and Reproduction. Ecology and Evolution, 2 , 2695-2709. http://dx.doi.org/10.1002/ece3.387

[43] Bresson, J., Varoquaux, F., Bontpart, T., Touraine, B. and Vile, D. (2013) The PGPR Strain Phyllobacterium brassicacearum STM196 Induces a Reproductive Delay and Physiological Changes That Result in Improved Drought Tolerance in Arabidopsis. New Phytologist, 200, 558-569. http://dx.doi.org/10.1111/nph.12383

[44] Vile, D., Pervent, M., Belluau, M., Vasseur, F., Bresson, J., Muller, B., Granier, C. and Simonneau, T. (2012) Arabidopsis Growth under Prolonged High Temperature and Water Deficit: Independent or Interactive Effects? Plant, Cell and Environment, 35, 702-718. http://dx.doi.org/10.1111/j.1365-3040.2011.02445.x

[45] He, W.M., Thelen, G.C., Ridenour, W.M. and Callaway, R.M. (2010) Is There a Risk to Living Large? Large Size Correlates with Reduced Growth When Stressed for Knapweed Populations. Biological Invasions, 12, 3591-3598. http://dx.doi.org/10.1007/s10530-010-9753-4

[46] Wolfe, M.D. and Tonsor, S.J. (2014) Adaptation to Spring Heat and Drought in Northeastern Spanish Arabidopsis thaliana. New Phytologist, 201, 323-334. http://dx.doi.org/10.1111/nph.12485

[47] Earley, E.J., Ingland, B., Winkler, J. and Tonsor, S.J. (2009) Inflorescences Contribute More than Rosettes to Lifetime Carbon Gain in Arabidopsis thaliana (Brassicaceae). American Journal of Botany, 96, 786-792. http://dx.doi.org/10.3732/ajb.0800149

[48] Dittmar, E.L., Oakley, C.G., Ågren, J. and Schemske, D.W. (2014) Flowering Time QTL in Natural Populations of Arabidopsis thaliana and Implications for Their Adaptive Value. Molecular Evolution, 23, 4291-4303. http://dx.doi.org/10.1111/mec.12857

[49] Wu, C.A., Lowry, D.B., Nutter, L.I. and Willis, J.H. (2010) Natural Variation for Drought-Response Traits in the Mimulus guttatus Species Complex. Oecologia, 162, 23-33. http://dx.doi.org/10.1007/s00442-009-1448-0

[50] Fulton, D.C., Stettler, M., Mettler, T., Vaughan, C.K., Li, J., Francisco, P., Gil, M., Reinhold, H., Eicke, S., Messerli, G., Dorken, G., Halliday, K., Smith, A.M., Smith, S.M. and Zeeman, S.C. (2008) $\beta$-AMYLASE4, a Noncatalytic Protein Required for Starch Breakdown, Acts Upstream of Three Active $\beta$-Amylases in Arabidopsis Chloroplasts. Plant Cell, 20, 1040-1058. http://dx.doi.org/10.1105/tpc.107.056507

[51] Chia, T., Thorneycroft, D., Chapple, A., Messerli, G., Chen, J., Zeeman, S.C., Smith, S.M. and Smith, A.M. (2004) A Cytosolic Glucosyltransferase Is Required for Conversion of Starch to Sucrose in Arabidopsis Leaves at Night. The Plant Journal, 37, 853-863. http://dx.doi.org/10.1111/j.1365-313X.2003.02012.x

[52] Niittylä, T., Messerli, G., Trevisan, M., Chen, J., Smith, A.M. and Zeeman, S.C. (2004) A Previously Unknown Maltose Transporter Essential for Starch Degradation in Leaves. Science, 303, 87-89.

http://dx.doi.org/10.1126/science.1091811

[53] Yu, T.S., Kofler, H., Hausler, R.E., Hille, D., Flugge, U.I., Zeeman, S.C., Smith, A.M., Kossmann, J., Lloyd, J. and Ritte, G. (2001) The Arabidopsis Sex1 Mutant Is Defective in the R1 Protein, a General Regulator of Starch Degradation in Plants, and Not in the Chloroplast Hexose Transporter. Plant Cell, 13, 1907-1918. http://dx.doi.org/10.1105/tpc.13.8.1907

[54] Caspar, T., Huber, S.C. and Somerville, C. (1985) Alterations in Growth, Photosynthesis, and Respiration in a Starchless Mutant of Arabidopsis thaliana (L.) Deficient in Chloroplast Phosphoglucomutase Activity. Plant Physiology, 79, 11-17. http://dx.doi.org/10.1104/pp.79.1.11

[55] Schneider, A., Häusler, R.E., Kolukisaoglu, U., Kunze, R., van der Graaff, E., Schwacke, R., Catoni, E., Desimone, M. 
and Flügge, U.I. (2002) An Arabidopsis thaliana Knock-Out Mutant of the Chloroplast Triose Phosphate/Phosphate Translocator Is Severely Compromised Only When Starch Synthesis, but Not Starch Mobilisation Is Abolished. Plant Journal, 32, 685-699. http://dx.doi.org/10.1046/j.1365-313X.2002.01460.x

[56] Van Houtte, H., Vandesteene, L., Lopez-Galvis, L., Lemmens, L., Kissel, E., Carpentier, S.C., Feil, R., Avonce, N., Beeckman, T., Lunn, J.E. and Van Dijck, P. (2013) Overexpression of the Trehalase Gene AtTRE1 Leads to Increased Drought Stress Tolerance in Arabidopsis and Is Involved in Abscisic Acid-Induced Stomatal Closure. Plant Physiology, 161, 1158-1171. http://dx.doi.org/10.1104/pp.112.211391

[57] McWatters, H.G., Bastow, R.M., Hall, A. and Millar, A.J. (2000) The ELF3 Regulates Light Signalling to the Circadian Clock. Nature, 408, 716-720. http://dx.doi.org/10.1038/35047079

[58] Eriksson, M.E., Hanano, S., Southern, M.M., Hall, A. and Millar, A.J. (2003) Response Regulator Homologues Have Complementary, Light-Dependent Functions in the Arabidopsis Circadian Clock. Planta, 218, 159-162. http://dx.doi.org/10.1007/s00425-003-1106-4

[59] Alonso, J.M., Hirayama, T., Roman, G., Nourizadeh, S. and Ecker, J.R. (1999) EIN2, a Bifunctional Transducer of Ethylene and Stress Responses in Arabidopsis. Science, 284, 2148-2152. http://dx.doi.org/10.1126/science.284.5423.2148

[60] Chang, C., Kwok, S.F., Bleecker, A.B. and Meyerowitz, E.M. (1993) Arabidopsis Ethylene-Response Gene ETR1-Similarity of Product to 2 Component Regulators. Science, 262, 539-544. http://dx.doi.org/10.1126/science.8211181

[61] Staswick, P.E., Su, W.P. and Howell, S.H. (1992) Methyl Jasmonate Inhibition of Root-Growth and Induction of a Leaf Protein Are Decreased in an Arabidopsis Mutant. Proceedings of the National Academy of Sciences, 89, 68376840. http://dx.doi.org/10.1073/pnas.89.15.6837

[62] Cao, H., Glazebrook, J., Clarke, J.D., Volko, S. and Dong, X.N. (1997) The Arabidopsis NPR1 Gene That Controls Systemic Acquired Resistance Encodes a Novel Protein Containing Ankyrin Repeats. Cell, 88, 57-63. http://dx.doi.org/10.1016/S0092-8674(00)81858-9

[63] Jirage, D., Tootle, T.L., Reuber, T.L., Frost, L.N., Feys, B.J., Parker, J.E., Ausubel, F.M. and Glazebrook, J. (1999) Arabidopsis thaliana PAD4 Encodes a Lipase-Like Gene That Is Important for Salicylic Acid Signaling. Proceedings of the National Academy of Sciences, 96, 13583-13588. http://dx.doi.org/10.1073/pnas.96.23.13583

[64] Wildermuth, M.C., Dewdney, J., Wu, G. and Ausubel, F.M. (2001) Isochorismate Synthase Is Required to Synthesize Salicylic Acid for Plant Defense. Nature, 414, 562-565. http://dx.doi.org/10.1038/35107108

[65] Bu, Q.Y., Jiang, H.L., Li, C.B., Zhai, Q.Z., Zhang, J.Y., Wu, X.Q., Sun, J.Q., Xie, Q. and Li, C.Y. (2008) Role of the Arabidopsis thaliana NAC Transcription Factors ANAC019 and ANAC055 in Regulating Jasmonic Acid-Signaled Defense Response. Cell research, 18, 756-767. http://dx.doi.org/10.1038/cr.2008.53

[66] Lu, P.L., Chen, N.Z., An, R., Su, Z., Qi, B.S., Ren, F., Chen, J. and Wang, X.C. (2007) A Novel Drought-Inducible Gene, $A T A F 1$, Encodes a NAC Family Protein That Negatively Regulates the Expression of Stress-Responsive Genes in Arabidopsis. Plant Molecular Biology, 63, 289-305. http://dx.doi.org/10.1007/s11103-006-9089-8

[67] Chen, Y., Yang, X., He, K., Liu, M., Li, J., Gao, Z., Lin, Z., Zhang, Y., Wang, X., Qiu, X., Shen, Y., Zhang, L., Deng, X., Luo, J., Deng, X.W., Chen, Z., Gu, H. and Qu, L.J. (2006) The MYB Transcription Factor Superfamily of Arabidopsis: Expression Analysis and Phylogenetic Comparison with the Rice MYB Family. Plant Molecular Biology, 60, 107-112. http://dx.doi.org/10.1007/s11103-005-2910-y

[68] Lee, J.Y., Colinas, J., Wang, J.Y., Mace, D., Ohler, U. and Benfey P.N. (2006) Transcriptional and Posttranscriptional Regulation of Transcription Factor Expression in Arabidopsis Roots. Proceedings of the National Academy of Sciences, 103, 6055-6056. http://dx.doi.org/10.1073/pnas.0510607103

[69] Li, Y.H., Sorefan, K., Hemmann, G. and Bevan, M.W. (2004) Arabidopsis NAP and PIR Regulate Actin-Based Cell Morphogenesis and Multiple Developmental Processes. Plant Physiology, 136, 3616-3627. http://dx.doi.org/10.1104/pp.104.053173

[70] Teng, S., Keurentjes, J., Bentsink, L., Koornneef, M. and Smeekens, S. (2005) Sucrose Specific Induction of Anthocyanin Biosynthesis in Arabidopsis Requires the MYB75/PAP1 Gene. Plant Physiology, 139, 1840-1852. http://dx.doi.org/10.1104/pp.105.066688 